\title{
Giant Ooids as One Kind of Anachronistic Sediments in Lower Triassic: A Case Study from Moyang Section, Guizhou Province, South China
}

\author{
Li Fei (李飞), Yan Jiaxin* (颜佳新) \\ Key Laboratory of Biogeology and Environmental Geology of Ministry of Education, China University of \\ Geosciences, Wuhan 430074, China
}

Lower Triassic carbonate ooids are widely distributed all over the world, from northern Italy to Germanic basin, extending across Turkey, Oman, Iran, and finally to Australia. South China and North Vietnam blocks in the paleo-equators in the eastern Tethys are also covered by extensive carbonate ooid deposits of Early Triassic. The oolite starts to develop after the Permian-Triassic mass extinction, and flourishes in the whole Early Triassic. Thus it is regarded as "disaster deposits". However, the Lower Triassic ooids are unusual in their relatively large dimension. Some of them are known as giant ooids, commonly developing in the Neoproterozoic, but rarely after the Cambrian. Because Lower Triassic giant ooids are not a local depositional phenomenon, found at the peripheral belt of the Yangtze platform, the isolated platform in the Nanpanjiang basin (South China), the Yidun block (southwestern China) and the Germanic basin, they seem to be one kind of anachronistic sediments.

A unique sedimentary condition in Early Triassic, especially the features of coeval depositional setting

This study was supported by the National Natural Science Foundation of China (No. 40472062).

*Corresponding author: jxyan@cug.edu.cn

(C) China University of Geosciences and Springer-Verlag Berlin Heidelberg 2010

Manuscript received December 22, 2009.

Manuscript accepted February 10, 2010. and seawater chemistry, seems to play a crucial role in the generation of the giant ooids after the biggest mass extinction in the Phanerozoic. Prevailing low-angel ramps or low-relief banks during that period provide numerous favorable bases for the growth of giant ooids. The upwelling of alkaline water from anoxic stratified ocean facilitates the formation of supersaturated shallow water. Simultaneously, hydrogen sulfide along with the upwelling would poison metazoans, and reduce the supply of ooid nuclei. The Lower Triassic giant ooids gradually diminish with the radiation of the Mesozoic biotas and the amelioration of marine environments.

At the studied section, Moyang of Guizhou, South China, the giant ooids are measured to be mostly between 2 and $6 \mathrm{~mm}$ in diameter, with some up to $12 \mathrm{~mm}$. Their nuclei predominantly consist of calcite grains and peloids. All of the giant ooids exhibit concentric laminae of tangentially oriented crystals, suggesting their origin of aragonitic minerals. Under SEM, authigenic carbonate fluorapatite (CFA) was observed, scattering discretely along ooid cortices. A couple of lines of evidence indicate that the CFA formed during early diagenesis. In addition, there are some calcified films and molds of filaments resembling remnants of microbes. The association of CFA with calcified filaments in the giant ooids would evince the unique paleoceanographic condition and the upwelling at that critical time. 